\title{
Thrombospondin-1 Levels in Patients with Coronary Heart Disease
}

\author{
Mohamed Elnoamany, Ashraf Dawood, Nahed Mohamed Momtaz, \\ Waleed Abdou
}

Cardiology Department, Faculty of Medicine, Menoufia University, Menoufia, Egypt

Email: nahed.mrm@gmail.com

How to cite this paper: Elnoamany, M., Dawood, A., Momtaz, N.M. and Abdou, W. (2021) Thrombospondin-1 Levels in Patients with Coronary Heart Disease. World Journal of Cardiovascular Diseases, 11, 277-291. https://doi.org/10.4236/wjcd.2021.116027

Received: May 9, 2021

Accepted: June 14, 2021

Published: June 17, 2021

Copyright $\odot 2021$ by author(s) and Scientific Research Publishing Inc. This work is licensed under the Creative Commons Attribution International License (CC BY 4.0).

http://creativecommons.org/licenses/by/4.0/ (c) (i) Open Access

\begin{abstract}
Background: Thrombospondin-1 (TSP1) is associated with atherosclerosis in animals with diabetes mellitus (DM), but the precise role of TSP-1 in human atherosclerosis remains unknown. Objectives: To investigate serum thrombospondin 1 level in patients with coronary artery disease with and without type $2 \mathrm{DM}$ and its relationship to coronary artery scoring systems. Methods: The study comprised 180 patients recruited from those underwent coronary angiography for suspected coronary artery disease (CAD) was approved by Institutional Review Board and Institutional Ethical Committee for Human Research of menoufia university hospital. They were divided according to presence of CAD and type $2 \mathrm{DM}$ into 4 groups: Group I ( $\mathrm{n}=44$ patients): Non diabetic subjects without CAD, Group II ( $\mathrm{n}=40$ patients): Diabetic patients without CAD, Group III ( $\mathrm{n}=49$ patients): Non diabetic patients with CAD and Group IV ( $\mathrm{n}=47$ patients): Diabetic patients with CAD. Serum level of TSP-1 was measured in all groups and coronary artery scoring analysis was done. Results: Serum TSP-1 levels were higher in patients with CAD and DM than in other groups $(\mathrm{P}<0.01)$ while the levels of serum TSP-1 in diabetic patients without CAD and non-diabetic patients with CAD didn't show significant difference. Plasma TSP-1 levels were higher in patients with DM than those in patients without DM $(582.95 \pm 55.70 \mathrm{ng} / \mathrm{mL}$ vs. $516.91 \pm$ $64.56 \mathrm{ng} / \mathrm{ml}, \mathrm{P}<0.001)$. Plasma levels of TSP-1 were higher in patients with CAD than those in patients without CAD $(569.54 \pm 68.16 \mathrm{ng} / \mathrm{mL}$ vs. $525.17 \pm$ $61.77 \mathrm{ng} / \mathrm{ml}, \mathrm{P}<0.001$ ). Patients with CAD and DM (group IV) had significantly higher severity score and vessel score than those with CAD only (group III) $(9.13 \pm 3.40,2.49 \pm 0.69$ vs. $7.37 \pm 3.16,2.02 \pm 0.80 \mathrm{ng} / \mathrm{ml}, \mathrm{P}<$ 0.05). Patients with three vessel disease had the highest serum TSP-1 level $(581.32 \pm 61.30 \mathrm{ng} / \mathrm{ml})$ when compared to patients with one or two vessel disease. The highest diagnostic performance of serum TSP-1 level in prediction of coronary artery disease was more pronounced in presence of DM
\end{abstract}


while the least diagnostic performance of serum TSP-1 was detected in absence of DM. Univariate logistic regression analysis of different variables for prediction of CAD showed that TSP-1 level was one of the independent predictors of CAD (OR 1.016, CI 1.010 - 1.023, P < 0.001). Conclusion: Serum TSP-1 level is higher in patients with CAD with and without type $2 \mathrm{DM}$ and its level is an independent predictor of CAD, but the diagnostic performance of serum TSP-1 level in prediction of CAD is more pronounced in presence of type $2 \mathrm{DM}$.

\section{Keywords}

Coronary Artery Disease, Diabetes Mellitus, Thrombospondin-1

\section{Introduction}

Thrombospondin-1 (TSP-1) is a large matricellular glycoprotein stored preformed in platelet $\alpha$-granules [1]. TSP-1 is released from platelets on activation that regulates cell-cell and cell-matrix interactions [2] [3] [4]. Expression of TSP-1 in the infarct border zone may limit the expansion of the granulation tissue and protect the non-infarcted myocardium from fibrotic remodeling [5]. TSP-1 down regulation in endothelial cell enhances angiogenesis [6]. TSP-1 inhibits tumor angiogenesis, so decreased tumor diameter and fewer tumor capillaries [7] [8].

TSP-1 also plays a role in inhibition of nitric oxide (NO), cyclic guanosine monophosphate (cGMP), cyclic adenosine monophosphate (cAMP) and vascular endothelial growth factor (VEGF) signaling, limiting blood flow, promoting thrombosis, and decreasing cellular and tissue survival. TSP-1 enhances inflammatory cell adhesion to and transmigration through the vascular endothelium. This, in turn, promotes atherosclerotic plaque formation [9].

Thrombospondin-1 may represent a link between DM and vascular complications [10]. TSP-1 promotes the pathological events associated with diabetic nephropathy such as mesangial cell proliferation and increased extracellular matrix production by mesangial cells [11] [12] [13] [14]. A peptide blocking the activation of transforming growth factor- $\beta$ by TSP-1 prevents the progression of cardiac fibrosis and improves cardiac function in a rat model, suggesting that TSP-1 plays an important role in the development of diabetics cardiomyopathy [15] [16]. Dysregulated matrix metalloproteinase activity contributes to vasculopathy in diabetes, and here too, TSP1 may play a role as vascular smooth muscle cell matrix metalloproteinase2 (VSMC MMP2) [17] and endothelial cells MMP9 [18] are upregulated by TSP1.

\section{Aim of the Work}

To investigate serum thrombospondin 1 (TSP-1) in patients with coronary artery disease (CAD) with and without type $2 \mathrm{DM}$ and its relationship (if any) to coro- 
nary artery scoring systems.

\section{Patients and Methods}

\subsection{Study Population}

This cross sectional observational study comprised 180 patients who underwent coronary angiography for suspected $\mathrm{CAD}$, they were divided according to the presence or absence of CAD and DM into 4 groups; Group I ( $\mathrm{n}=44$ patients) non diabetic subjects without CAD, Group II ( $\mathrm{n}=40$ patients) diabetic patients without CAD, Group III ( $\mathrm{n}=49$ patients) non diabetic patients with CAD and Group IV ( $\mathrm{n}=47$ patients) diabetic patients with CAD. The study was performed prospectively in the period from September 2018 to June 2019 in Menoufia University Hospital Catheterization Laboratory. The study was approved by the appropriate Institutional Review Board and Institutional Ethical Committee for Human Research. All study subjects provided written informed consent regarding the study procedures.

DM was diagnosed according to World Health Organization (WHO) and the American Diabetes Association (ADA) as fasting blood glucose $\geq 126 \mathrm{mg} / \mathrm{dl}$ ( $\geq 7$ $\mathrm{mmol} / \mathrm{L}$ ) or 2 hour post prandial blood glucose $\geq 200 \mathrm{mg} / \mathrm{dl}(\geq 11.1 \mathrm{mmol} / \mathrm{L})$, or random blood glucose $\geq 200 \mathrm{mg} / \mathrm{dl}$ and presence of diabetes symptoms, or $\mathrm{HbAlc} \geq 6.5 \mathrm{gm} / \mathrm{dl}[19]$.

Inclusion criteria: Patients included in the study are those undergoing diagnostic coronary angiography for suspected CAD with one or more of the following:

Typical ischemic chest pain; Electrocardiographic (ECG) changes suggesting CAD; Previous admission to hospital by CAD; Previous cardiac interventions e.g. percutaneous coronary intervention (PCI), coronary artery bypass graft (CABG) or other investigations suggesting $\mathrm{CAD}$ such as positive exercise stress test, positive myocardial perfusion imaging or echocardiographic regional wall motion abnormality suggesting CAD.

Exclusion criteria: Patients with type I DM, more than mild valvular heart disease, congestive heart failure NYHA class III or IV, atrial fibrillation, history of malignancy or autoimmune diseases were excluded from the study.

\subsection{The Study Populations Were Subjected to}

1) Complete history taking.

2) Thorough clinical evaluation.

3) 12-lead resting ECG.

4) Conventional echocardiographic examination.

5) Coronary angiography.

\subsubsection{Conventional Echocardiography}

All subjects were examined in the left lateral decubitus position according to the recommendations of the American Society of cardiology [20], Conventional 
echocardiographic Doppler study was done using Vivid 9, General Electric Healthcare (GE Vingmed, Norway). With the use of the long axis parasternal, apical 4, 5 and 2-chamber views, all patients underwent conventional $\mathrm{M}$ mode and 2-D echocardiographic examination. Visual assessment of regional wall motion was performed. End systolic volume, end diastolic volume (by manual tracing of endocardial borders) and ejection fraction of each ventricle was calculated using Simpson's rule [20]. Assessment of LV mass and LV mass index (LVMI): by using the previous measured parameters, LVM was calculated using the formula that has been proposed by Devereux [21]. Conventional (continuous-wave and color) Doppler valvular flow was determined.

\subsubsection{Coronary Angiography}

Angiographic analysis: diagnostic coronary angiography was carried out in all patients using Judkins technique. Quantitative analysis of coronary arteries was performed with the computer-assisted coronary angiography analysis system. End-diastolic frames from each arteriogram were selected for analysis. The percentage diameter stenosis was assessed in different projections and the highest value of each lesion was chosen. Images of the coronary tree were obtained with the Seimens set system and reviewed by an experienced cardiologist who had no knowledge of the patients' biochemical results to assess the extent and severity of CAD.

\subsubsection{The Coronary Tree Was Divided into 16 Segments as Follows}

The left main coronary artery (LMCA) as one segment, the left anterior descending (LAD) artery was divided into: proximal, mid, distal segments beside two diagonals $\mathrm{Dl}$ and $\mathrm{D} 2$, the left circumflex (LCX) artery was divided into: proximal, mid, distal segments beside two marginal branches $\mathrm{OMl}$ and $\mathrm{OM} 2$, the right coronary (RCA) artery was divided into: proximal, mid, distal segments beside posterior descending artery (PDA) and posterolateral branch (PL).

\subsubsection{Coronary Angiography Was Scored According to}

Vessel score [22]: this is the number of vessels with a significant stenosis ( $50 \%$ or greater reduction in lumen diameter). Scores ranged from 0 to 3 , depending on the vessels involved. Left main artery stenosis is scored as single vessel disease [22].

Severity score [23]: the coronary circulation will be divided into eight proximal segments. Disease in the distal segments will be not considered because of difficulty in quantitating the severity of lesions in these areas. The eight proximal segments scored included the left main coronary artery, the left anterior descending artery (LAD) up to the junction of the middle and distal thirds of the vessel, the proximal third of the major diagonal branch of the LAD, the left circumflex coronary artery (LCX) up to the junction of the middle and distal thirds of the vessel, the proximal third of the major obtuse marginal branch of the LCX, the right coronary artery (RCA) up to and including the origin of posterior descending artery (PDA), the proximal third of the PDA. In cases in which the 
PDA was supplied by the LCX (LCX dominance) lesions in the LCX up to the origin of the PDA were included, as were lesions of the RCA up to the origin of the middle and distal third of the vessel. The severity of the proximal coronary disease will be assessed by assigning points to each lesion as follows: less than $50 \%$ stenosis of the luminal diameter, (1 point); $50 \%$ to $74 \%$ stenosis, ( 2 points); $75 \%$ to $99 \%$ stenosis, (3 points); total obstruction, (4 points). The points for each lesion in the proximal coronary circulation will be summed and a score for severity of coronary atherosclerosis will be obtained [23].

Gensini's score [24] [25]: the Gensini score will be calculated for each patient and computed by assigning a severity score to each coronary stenosis according to the degree of luminal narrowing and its importance based on location. More specifically, reductions of $25 \%, 50 \%, 75 \%, 90 \%, 99 \%$ and complete occlusion will be given Gensini score of 1, 2, 4, 8, 16 and 32, respectively. Each principal vascular segment will be assigned a multiplier in accordance with the functional significance of the myocardial area supplied by that segment, that is, the LM will be assigned the significant multiplier $\times 5$; the proximal segment of the LAD will be given $\times 2.5$; the proximal segment of the LCX will be weighted by a factor of $\times$ 2.5; the mid segment of the LAD will be assigned a factor of $\times 1.5$; the RCA, the distal segment of the LAD, mid and distal segment of LCX, the posterior descending artery, and the obtuse marginal artery will be all given $\times 1$; and all other areas will be assigned a factor of $\times 0.5$ [24] [25].

SYNTAX SCORE [26]: was calculated by a computer program consisting of sequential and interactive self-guided questions. The algorithm consists of 12 main questions. The first three questions determine the dominance, the total number of lesions and the vessel segments involved per lesion, the maximum number of lesions allowed is twelve and each lesion is characterized by a number, 1 to 12. The last nine questions refer to adverse lesion characteristics and are repeated for each lesion. The first question is referring to a total occlusion; if a total occlusion is scored, answers should be given to detailed sub-questions. The last of these sub-questions refers to the absence or presence of side branches and their size. If multiple lesions were less than 3 vessel reference diameters apart, these lesions were scored as being one lesion. However, lesions at a greater distance from each other (more than 3 vessel reference diameters), were scored as separate lesions [26].

The total SYNTAX score was derived from the summation of these individual scorings. After the completion of the algorithm a report was automatically generated summarizing all the adverse characteristics and the individual scoring of each lesion as well as the total SYNTAX score [26].

\subsection{Laboratory Examination}

Blood was sampled on admission to measure blood glucose, HbA1c, serum total cholesterol (TC), triglycerides (TG), high density lipoprotein-cholesterol (HDL-C), and high sensitive C-reactive protein (hs-CRP) concentrations were determined by enzymatic colorimetric test. LDL cholesterol was estimated by Friedewald's 
formula [27]. The glycated hemoglobin (HbAlc) level indicates the mean blood glucose level during the previous 2 to 3 months.

After an overnight fast, blood samples for TSP-1 were withdrawn at the time of coronary angiography, before administration of contrast agent or medications. Samples were allowed to clot for 2 hours at room temperature before centrifugation for 15 minutes. The supernatant was collected and carried out the assay immediately.

$100 \mu \mathrm{L}$ sample was added to each well and Incubated 90 minutes at $37^{\circ} \mathrm{C}$. Then, $100 \mu \mathrm{L}$ Biotinylated Detection Ab was added and incubated 1 hour at $37^{\circ} \mathrm{C}$ and aspirated and washed 3 times. After that, add $100 \mu \mathrm{L}$ HRP Conjugate and incubated 30 minutes at $37^{\circ} \mathrm{C}$ and aspirated and washed 5 times. Then, 90 $\mu \mathrm{L}$ Substrate Reagent was added and incubated 15 minutes at $37^{\circ} \mathrm{C}$. Then, add 50 $\mu \mathrm{L}$ Stop Solution and Read at $450 \mathrm{~nm}$ immediately and calculation of results.

\section{Statistical Analysis}

Data were fed to the computer and analyzed using IBM SPSS software package version 20.0. (Armonk, NY: IBM Corp). Qualitative data expressed as number and percentage and analyzed by Chi-square (X2) or Fisher exact test when appropriate.

Comparisons between means were evaluated by unpaired t-test or ANOVA (F) test (with post hoc test) for continuous variables with determination of the least significant difference (LSD) by pair wise comparison between group means, and by chi-square test for proportions. Pearson's correlation coefficient analysis was used to assess the association between measured parameters.

Multivariate logistic regression was used to assess in dependent predictors of coronary artery disease among patients using, demographic, clinical, laboratory and echocardiographic variables. Level of significance was set as ( $\mathrm{P}$ value $<0.05$ ).

\section{Results}

The study comprised 180 patients who underwent coronary angiography for suspected CAD, they were divided according to the presence or absence of CAD and DM into 4 groups; Group I ( $\mathrm{n}=44$ patients, 21 males and 23 females with mean age $53.91 \pm 7.10$ years) non diabetic subjects without CAD, Group II ( $\mathrm{n}=$ 40 patients, 17 males and 23 females with mean age $53.50 \pm 7.27$ years) diabetic patients without CAD, Group III ( $\mathrm{n}=49$ patients, 45 males and 4 females with mean age $54.96 \pm 8.04$ years) non diabetic patients with CAD and Group IV ( $\mathrm{n}=$ 47 patients, 27 males and 20 females with mean age $57.53 \pm 6.43$ years) diabetic patients with CAD.

Patients in group IV (DM and CAD) were older, had higher BMI and higher prevalence of HTN $(\mathrm{P}<0.001)$. HbA1C TC, TG, LDL as well as hsCRP were significantly higher in group IV compared to other groups $(P<0.001)$. Serum TSP-1 was significantly higher in group II and group III compared to group I. In group IV, serum TSP-1 was significantly higher than the other 3 groups $(\mathrm{P}<$ 
0.001) (Table 1). regarding coronary artery scores in patients with CAD (groups III \& IV), severity score and vessel score were significantly higher in group IV compared to group III while there was no significant differences between the two groups regarding Syntax score and Gensini score (Table 1).

The smoking rate was significantly higher in group III and IV compared to each of group I and group II. The incidence of hypertension was significantly higher in group IV compared to other groups (higher in patients with DM than that in patients without DM). BMI was significantly higher in group IV compared to other groups. Patients with CAD were older compared to patients without CAD regardless of DM. EF was significantly higher in groups I and II compared to other groups. LV mass index was significantly higher in group I compared to other groups. Glycated hemoglobin (HbA1c) was significantly higher in diabetic groups (group II and group IV) in comparison to non-diabetic groups (group I and group III) $\mathrm{P}<0.001$. hs-CRP was significantly higher in group IV compared to other groups $(\mathrm{P}<0.001)$. Total cholesterol was significantly

Table 1. Baseline demographic, clinical and laboratory characteristics and coronary angiographic scores of studied groups.

\begin{tabular}{|c|c|c|c|c|c|}
\hline & $\begin{array}{l}\text { Group I } \\
(\mathrm{n}=44)\end{array}$ & $\begin{array}{l}\text { Group II } \\
(n=40)\end{array}$ & $\begin{array}{c}\text { Group III } \\
(n=49)\end{array}$ & $\begin{array}{c}\text { Group IV } \\
(n=47)\end{array}$ & $\mathrm{p}$ \\
\hline Sex (male/female) & $21 / 23$ & $17 / 23$ & $45 / 4$ & $27 / 20$ & $<0.001^{*}$ \\
\hline Age & $53.91 \pm 7.10$ & $53.50 \pm 7.27$ & $54.96 \pm 8.04$ & $57.53^{\#} \pm 6.43$ & $0.04^{*}$ \\
\hline BMI & $26.55 \pm 2.09$ & $27.99 \pm 2.56$ & $27.77 \pm 2.34$ & $30.43^{* \# \Delta} \pm 3.56$ & $<0.001^{*}$ \\
\hline HTN (\%) & 52.3 & 65.0 & 34.7 & 80.9 & $<0.001^{*}$ \\
\hline Smoking (\%) & 25.0 & 17.5 & 65.3 & 29.8 & $<0.001^{*}$ \\
\hline LVEF (\%) & $60.32 \pm 6.49$ & $58.88 \pm 8.75$ & $54.53^{*} \pm 8.13$ & $53.02^{\star \#} \pm 8.28$ & $<0.001^{*}$ \\
\hline $\mathrm{LV}$ mass index $\left(\mathrm{gm} / \mathrm{m}^{2}\right)$ & $96.34 \pm 30.16$ & $93.75 \pm 28.70$ & $78.63^{* \#} \pm 24.98$ & $92.64 \pm 23.51$ & $0.01^{*}$ \\
\hline S. Creatinine (mg/dl) & $0.93 \pm 0.15$ & $0.94 \pm 0.15$ & $0.98 \pm 0.17$ & $0.99 \pm 0.18$ & NS \\
\hline $\mathrm{HbAlc}(\%)$ & $5.22 \pm 0.51$ & $7.14^{\star} \pm 0.59$ & $5.56^{* \#} \pm 0.37$ & $8.51^{* \# \Delta} \pm 0.53$ & $<0.001^{*}$ \\
\hline hs-CRP (mg/dl) & $0.59 \pm 0.17$ & $0.74 \pm 0.19$ & $0.79 \pm 0.21$ & $3.39^{* \# \Delta} \pm 1.25$ & $<0.001^{*}$ \\
\hline Total cholesterol (mg/dl) & $180.7 \pm 11.49$ & $195.6^{*} \pm 14.42$ & $256.9^{* \#} \pm 28.46$ & $283.0^{* \# \Delta} \pm 17.77$ & $<0.001^{*}$ \\
\hline Triglycerides (mg/dl) & $95.61 \pm 20.73$ & $166.53^{*} \pm 41.01$ & $217.55^{* \#} \pm 113.80$ & $272.68^{* \# \Delta} \pm 69.77$ & $<0.001^{*}$ \\
\hline HDL-C (mg/dl) & $38.91 \pm 3.87$ & $33.70^{*} \pm 2.67$ & $31.45^{\star \#} \pm 2.11$ & $31.13^{* \# \Delta} \pm 2.03$ & $<0.001^{*}$ \\
\hline LDL-C (mg/dl) & $122.5 \pm 8.79$ & $128.7 \pm 10.61$ & $179.67^{\star \#} \pm 19.07$ & $197.4^{\star \# \Delta} \pm 14.58$ & $<0.001^{*}$ \\
\hline TSP-1 (ng/mL) & $498.11 \pm 57.10$ & $554.92^{\star} \pm 52.85$ & $533.80^{*} \pm 66.73$ & $606.81^{* \# \Delta} \pm 46.57$ & $<0.001^{*}$ \\
\hline Severity score & - & - & $7.37 \pm 3.16$ & $9.13 \pm 3.40$ & $0.008^{*}$ \\
\hline Gensini's score & - & - & $54.73 \pm 42.97$ & $59.28 \pm 42.05$ & 0.37 \\
\hline Syntax score & - & - & $16.45 \pm 10.48$ & $18.49 \pm 9.92$ & 0.26 \\
\hline Vessel score & - & - & $2.02 \pm 0.80$ & $2.49 \pm 0.69$ & $0.003^{*}$ \\
\hline One (n) & - & - & 15 & 5 & \\
\hline Two (n) & - & - & 18 & 14 & $0.013^{*}$ \\
\hline Three (n) & - & - & 16 & 28 & \\
\hline
\end{tabular}

BMI, body mass index; LVEF, left ventricular ejection fraction; LVMI, left ventricular mass index; HbAlc, glycated hemoglobin; HDL, high density lipoproteins; LDL, low density lipoproteins; NS, non significant; *: Group I vs other groups, *: Group II vs other groups, $\Delta$ : Group III vs other groups. 
higher in group IV compared to other groups and in group III in comparison to groups I and II, while triglycerides were significantly higher in all groups compared to group I and in group IV in comparison to group II and III $\mathrm{P}<0.001$. HDL cholesterol was significantly higher in group I in comparison to other groups, $\mathrm{P}<0.001$. LDL cholesterol was significantly higher in all groups compared to group I, while it was significantly higher in group IV in comparison to group II and group III and in group III compared to group II, $(\mathrm{P}<0.001)$. Patients with CAD and DM (group IV) had significantly higher severity score and vessel score than those with CAD only (group III) $(\mathrm{P}<0.05)$ (Table 1).

Serum TSP-1 level was significantly higher in all groups compared to group I (non-diabetic subjects without CAD) while was significantly higher in diabetic patients with CAD (group IV) compared to that in diabetic patients without CAD (group II) and non-diabetic patients with CAD (group III). When patients were divided into two groups according to DM, plasma TSP-1 levels were higher in patients with DM than those in patients without DM $(582.95 \pm 55.70 \mathrm{ng} / \mathrm{mL}$ vs $516.91 \pm 64.56 \mathrm{ng} / \mathrm{ml}, \mathrm{P}<0.001$ ) (Table 2 ). When patients were divided into two groups based on the presence of CAD, plasma levels of TSP-1 were higher in patients with CAD than those in patients with non CAD $(569.54 \pm 68.16 \mathrm{ng} / \mathrm{mL}$ vs $525.17 \pm 61.77 \mathrm{ng} / \mathrm{ml}, \mathrm{P}<0.001$ ) (Table 2).

Patients with vessel score 3 had higher serum TSP-1 levels (581.32 \pm 61.30$)$ than patients with vessel score 2 (564.97 \pm 77.05$)$, the latter group had also higher serum TSP-1 levels than patients with vessel score $1(550.95 \pm 65.72)$ though the differences among groups were not statistically significant $(\mathrm{P}$-value $>0.05)$ (Table 3).

Serum TSP-1 showed significant direct correlations with BMI $(\mathrm{r}=0.315, \mathrm{P}<$ 0.001), HBA1C $(r=0.570, P<0.001)$, hs-CRP $(r=0.493, P<0.001), T C(r=$ $0.380, \mathrm{P}<0.001)$, TG $(\mathrm{r}=0.341, \mathrm{P}<0.001)$ and LDL $(\mathrm{r}=0.357, \mathrm{P}<0.001)$ while it showed significant inverse correlations with $\operatorname{HDL}(\mathrm{r}=-0.335, \mathrm{P}<0.001)$ and

Table 2. Statistical comparison between Non diabetes mellitus and diabetes mellitus, non-coronary artery disease and coronary artery disease groups regarding serum Thrombospondin-1 (TSP-1).

\begin{tabular}{ccccccc}
\hline & $\begin{array}{c}\text { Group I \& III } \\
(\text { Non-DM) } \\
(\mathrm{n}=93)\end{array}$ & $\begin{array}{c}\text { Group II \& IV } \\
(\mathrm{DM}) \\
(\mathrm{n}=87)\end{array}$ & $\mathbf{P}$ & $\begin{array}{c}\text { Group I \& II } \\
(\text { Non-CAD }) \\
(\mathrm{n}=84)\end{array}$ & $\begin{array}{c}\text { Group III \& IV } \\
(\text { CAD }) \\
(\mathrm{n}=96)\end{array}$ \\
\hline $\begin{array}{c}\text { Serum } \\
\text { Thrombospondin-1 } \\
(\mathrm{TSP}-1)(\mathrm{ng} / \mathrm{mL})\end{array}$ & $516.91 \pm 64.56$ & $582.95 \pm 55.70$ & $<0.001^{*}$ & $525.17 \pm 61.77$ & $569.54 \pm 68.16<$ & $<0.001^{*}$ \\
\hline
\end{tabular}

CAD, coronary artery disease; DM, diabetes mellitus; TSP-1, thrombospondin-1.

Table 3. Thrombospondin-1 (TSP-1) frequencies in different vessel score.

\begin{tabular}{ccccc}
\hline & \multicolumn{4}{c}{ Vessel score } \\
\cline { 2 - 4 } Items & One & Two & Three & P \\
\hline Serum Thrombospondin-1 (TSP-1) $(\mathrm{ng} / \mathrm{mL})$ & $551 \pm 65.7$ & $565 \pm 77.1$ & $581.3 \pm 61.3$ & NS \\
\hline
\end{tabular}

NS, non-significant. 
$\mathrm{EF}(\mathrm{r}=-0.157, \mathrm{P}=0.035)$. There were no significant correlations between serum TSP-1 and all coronary angiography scoring systems (Table 4).

At cutoff value $>545 \mathrm{ng} \backslash \mathrm{ml}$ serum TSP-1 level demonstrated a diagnostic sensitivity of $91.5 \%$, a diagnostic specificity of $79.6 \%$ and accuracy of $85.7 \%$ in discriminating the group of diabetes and CAD (group IV) from control group (group I). It also showed a diagnostic sensitivity of $70.8 \%$, a diagnostic specificity of $79.6 \%$ and accuracy of $73.6 \%$ at cutoff value $>545 \mathrm{ng} \backslash \mathrm{ml}$ when differentiating between coronary artery disease group (CAD) (groups III \& group IV) and control group (group I). Similarly, At cutoff value $>545$, serum TSP-1 level demonstrated a diagnostic sensitivity of $51.0 \%$, a diagnostic specificity of $79.6 \%$ and accuracy (efficacy) of $64.5 \%$ in discriminating non-diabetic patients with CAD (group III) from control group (group I) (Table 5).

The diagnostic performance of serum TSP-1 level in prediction of coronary artery disease is more pronounced in presence of diabetes mellitus (AUC = 0.930 ) with $85.7 \%$ accuracy while the least diagnostic performance of serum TSP-1 was detected in absence of diabetes mellitus (AUC $=0.655$ ) with $64.5 \%$

Table 4. Correlations between serum TSP-1 and other variables.

\begin{tabular}{|c|c|c|}
\hline \multirow{2}{*}{ Variables } & \multicolumn{2}{|c|}{ Serum thrombospondin-1 (TSP-1) (ng/mL) } \\
\hline & $\mathbf{r}$ & $\mathbf{P}$ \\
\hline BMI & $0.315^{\star}$ & $<0.001^{*}$ \\
\hline HbAlc (\%) & $0.570^{*}$ & $<0.001^{*}$ \\
\hline hs-CRP (mg/dl) & $0.493^{*}$ & $<0.001^{*}$ \\
\hline Total cholesterol (mg/dl) & $0.380^{*}$ & $<0.001^{*}$ \\
\hline Triglycerides (mg/dl) & $0.341^{*}$ & $<0.001^{*}$ \\
\hline $\mathrm{HDL}-\mathrm{C}(\mathrm{mg} / \mathrm{dl})$ & $-0.335^{\star}$ & $<0.001^{*}$ \\
\hline LDL-C (mg/dl) & $0.357^{\star}$ & $<0.001^{*}$ \\
\hline $\mathrm{EF}(\%)$ & $-0.157^{\star}$ & $0.035^{*}$ \\
\hline Vessel score & 0.176 & 0.086 \\
\hline Severity score & 0.086 & 0.404 \\
\hline Gensini's score & -0.067 & 0.519 \\
\hline Syntax score & -0.055 & 0.594 \\
\hline
\end{tabular}

r: Pearson coefficient; *: Statistically significant at $\mathrm{p} \leq 0.05$; BMI, body mass index; EF, ejection fraction; HBA1C, glycated hemoglobin; HDL, high density lipoproteins; hs-CRP, high sensitive C-reactive protein; LDL, low density lipoproteins, TSP-1, thrombospondin-1.

Table 5. Diagnostic performance of serum Thrombospondin-1 (TSP-1) (ng/mL) between different studied groups.

\begin{tabular}{ccccccccc}
\hline & Cutoff & Sensitivity & Specificity & PPV & NPV & Accuracy & AUC & P value \\
\hline Group I \& Group III & $>545$ & $51.0 \%$ & $79.6 \%$ & $73.5 \%$ & $59.3 \%$ & $64.5 \%$ & $0.655^{*}$ & $0.010^{*}$ \\
Group I \& Group IV & $>545$ & $91.5 \%$ & $79.6 \%$ & $82.7 \%$ & $89.7 \%$ & $85.7 \%$ & $0.930^{*}<0.001^{*}$ \\
$\begin{array}{c}\text { Group I \& Group } \\
\text { CAD (III + IV) }\end{array}$ & $>545$ & $70.8 \%$ & $79.6 \%$ & $88.3 \%$ & $55.6 \%$ & $73.6 \%$ & $0.790^{*}<0.001^{*}$ \\
\hline
\end{tabular}


Table 6. Univariate and multivariate analysis of predictors of coronary artery diseases in studied populations.

\begin{tabular}{ccccccc}
\hline & \multicolumn{7}{c}{ Presence of CAD } \\
\cline { 2 - 7 } & \multicolumn{7}{c}{ Univariate } & & & \# Multivariate \\
\cline { 2 - 7 } & OR & $(95 \%$ C.I $)$ & p & OR & $(95 \%$ C.I $)$ & p \\
\hline Smoking & 2.760 & $(1.251-6.089)$ & $\mathbf{0 . 0 1 2}^{*}$ & 9.299 & $(0.224-385.7)$ & 0.241 \\
BMI (kg/m $)$ & 1.437 & $(1.205-1.714)$ & $<0.001^{*}$ & 1.141 & $(0.639-2.039)$ & 0.656 \\
HDL-C (mg/dl) & 0.440 & $(0.327-0.591)$ & $<0.001^{*}$ & 0.826 & $(0.506-1.348)$ & 0.445 \\
LDL-C (mg/dl) & 1.211 & $(1.081-1.358)$ & $\mathbf{0 . 0 0 1}^{*}$ & 1.218 & $(1.018-1.456)$ & $\mathbf{0 . 0 3 1 ^ { * }}$ \\
HbA1C (\%) & 9.112 & $(3.182-26.092)$ & $<0.001^{*}$ & 0.405 & $(0.032-5.110)$ & 0.485 \\
TSP-1 (mg/dl) & 1.016 & $(1.010-1.023)$ & $<0.001^{*}$ & 1.025 & $(0.988-1.062)$ & 0.184 \\
\hline
\end{tabular}

OR: Odd's ratio, C.I: Confidence interval, *: All variables with $\mathrm{P}<0.05$ was included in the multivariate. *: Statistically significant at $\mathrm{p} \leq 0.05$.

accuracy (Table 5).

\section{Logistic Regression Analysis}

A simple logistic regression analysis was done for different variables for prediction of CAD and it revealed that smoking [OR 2.760, CI (1.251 - 6089), P < 0.05 ], BMI [OR 1.437, CI (1.205 - 1.714), P < 0.001], HDL-C [OR 0.440, CI (0.327 - 0.591), $\mathrm{P}<0.001$ ], LDL-C [OR 1.211, CI (1.081 - 1.358), $\mathrm{P}<0.001$ ], HbA1c [OR 9.112, CI (3.182 - 26.092), P < 0.001], TSP-1 [OR 1.016, CI (1.010 $1.023), \mathrm{P}<0.001]$ were independent predictors of CAD. Simple logistic regression analysis variables with a $\mathrm{P}<0.05$ were entered into a multivariate logistic model and the analysis revealed that LDL-C [OR 1.218, CI (1.018 - 1.456), $\mathrm{P}<$ 0.05 ) was significantly independent predictor of CAD (Table 6).

\section{Discussion}

Thrombospondin-1 (TSP-1) plays pivotal role in atherogenesis. The expression of TSP-1 has been demonstrated to increase in VSMC in human atherosclerotic lesions [28], which may contribute to inflammation and atherogenesis. Hypoxia induces the migration of the coronary artery SMCs, which is elicited by TSP-1 [29] [30]. An additional study identified that TSP-1 modulates smooth muscle cell migration, which may accelerate atherosclerotic lesion development [31]. TSP-1 infiltrates into nascent atherosclerotic plaques and promotes atherogenesis through binding of thrombospondin-1 to human plasma lipoprotein mainly very low density lipoprotein (VLDL) [32] [33].

Vascular smooth muscle cell (VSMC) migration and proliferation are key events in the development of atherosclerotic lesions. VSMCs from patients with diabetes exhibit increased proliferation, adhesion, and migration. Stimulating VSMCs through increased levels of TSP-1 in the diabetic vessel wall may explain the enhanced proliferation of VSMCs [34] [35].

Few studies of the effect of TSP-1 on CAD have been performed in humans. 
McGillicuddy et al. [36] showed that fluvastatin decreases TSP-1 expression and abolishes the ability of transforming growth factor- $\beta 1$ to induce TSP- 1 expression in cultured human coronary artery smooth muscle cells. Recent studies have linked the TSP family, including TSP-1, to the development of atherosclerosis at the genetic level [37] [38] [39].

The present study was designed to evaluate serum levels of Thrombospondin-1 and in patients as regards presence and/or absence of coronary artery disease and type 2 DM and show a link between human plasma TSP-1 concentrations and CAD in patients with or without DM.

To the best of our knowledge there are just few studies in the literature that focused on measurement of the level of thrombospondin-1 in patients with CAD and DM and studied its relationship to CAD severity scoring systems.

In our study, there were highly significant difference between all studied groups as regarding serum Thrombospondin-1 levels, highly statistical difference was present between patients with CAD (Groups III \& IV) and those without CAD (Groups I \& II) and highly statistical difference was present between patients with DM (Groups II \& IV) and those without DM (Groups I \& III), this means that there is a direct relation between serum TSP-1 levels and coronary atherosclerosis and increase more in presence of diabetes with CAD.

In our study, serum TSP-1 level was significantly higher in CAD patients compared to healthy control individuals, also TSP-1 levels were found to be highly significant when diabetic CAD patients were compared to non-diabetic CAD patients. We found that plasma TSP-1 levels were higher in diabetic mellitus with coronary artery disease patients than those in other patients. In agreement with our study, the study by Kyu-Young Choi et al. [40] reported that the plasma TSP-1 concentration was higher in diabetic patients with CAD patients compared to other patients.

Several mechanisms have been suggested for the effect of higher plasma TSP-1 level on atherosclerosis in patients with DM [41]. First, dysfunction of endothelial cells (ECs) in patients with DM is well known [42] and TSP-1 certainly contributes to this dysfunction because of its antiproliferative and apoptotic effects on ECs [43] [44]. Second, although TSP-1 in diabetic vessels may affect metabolism of the luminal EC monolayer and VSMCs, the large amounts of TSP-1 present in the adventitia ultimately results in compromised growth and remodeling of the vasa vasorum, this may lead to ischemic conditions in the inner layers of the vessel wall, and such oxygen stress could stimulate VSMC proliferation and initiate atherosclerotic lesions [41]. Third, TSP1 activates latent transforming growth factor- $\beta$ (TGF- $\beta$ ) [45] [46] which promotes diabetic-associated atherosclerotic plaque formation [47].

\section{Study Limitations}

First, the medications for the patients were not standardized before randomization; they were on different types and doses of medications for CAD and di- 
abetes that may have a potential effect on the inflammatory process and levels of TSP-1. Second, the study lacked a large validation population. Further prospective studies are thus needed to confirm our results.

\section{Conclusion}

Plasma TSP-1 level is increased in patients with CAD with and without type 2 DM. TSP-1 is considered an independent predictor for CAD though the diagnostic performance of serum TSP-1 level in prediction of CAD is more pronounced in the presence of type $2 \mathrm{DM}$.

\section{Conflicts of Interest}

The authors declare no conflicts of interest regarding the publication of this paper.

\section{References}

[1] Lawler, J. (2000) The Functions of Thrombospondin-1 and -2. Current Opinion in Cell Biology, 12, 634-640. https://doi.org/10.1016/S0955-0674(00)00143-5

[2] Baenziger, N.L., Brodie, G.N. and Majerus, P.W. (1971) A Thrombin-Sensitive Protein of Human Platelet Membranes. Proceedings of the National Academy of Sciences, 68, 240-243. https://doi.org/10.1073/pnas.68.1.240

[3] Bornstein, P. (1995) Diversity of Function Is Inherent in Matricellular Proteins: An Appraisal of Thrombospondin 1. The Journal of Cell Biology, 130, 503-506. https://doi.org/10.1083/jcb.130.3.503

[4] Adams, J.C. (2001) Thrombospondins: Multifunctional Regulators of Cell Interactions. Annual Review of Cell and Developmental Biology, 17, 25-51. https://doi.org/10.1146/annurev.cellbio.17.1.25

[5] Frangogiannis, N.G., Ren, G., Dewald, O., Zymek, P., Haudek, S., Koerting, A., Entman, M.L., et al. (2005) Critical Role of Endogenous Thrombospondin-1 in Preventing Expansion of Healing Myocardial Infarcts. Circulation, 111, 2935-2942. https://doi.org/10.1161/CIRCULATIONAHA.104.510354

[6] DiPietro, L.A., Nebgen, D.R. and Polverini, P.J. (1994) Downregulation of Endothelial Cell Thrombospondin 1 Enhances in Vitro Angiogenesis. Journal of Vascular Research, 31, 178-185. https://doi.org/10.1159/000319585

[7] Rodríguez-Manzaneque, J.C., Lane, T.F., Ortega, M.A., Hynes, R.O., Lawler, J. and Iruela-Arispe, M.L. (2001) Thrombospondin-1 Suppresses Spontaneous Tumor Growth and Inhibits Activation of Matrix Metalloproteinase-9 and Mobilization of Vascular Endothelial Growth Factor. Proceedings of the National Academy of Sciences, 98, 12485-12490. https://doi.org/10.1073/pnas.171460498

[8] Isenberg, J.S., Hyodo, F., Ridnour, L.A., Shannon, C.S., Wink, D.A., Krishna, M.C. and Roberts, D.D. (2008) Thrombospondin 1 and Vasoactive Agents Indirectly Alter Tumor Blood Flow. Neoplasia, 10, 886-896. https://doi.org/10.1593/neo.08264

[9] Koltsova, E.K., Hedrick, C.C. and Ley, K. (2013) Myeloid Cells in Atherosclerosis: A Delicate Balance of Anti-Inflammatory and Proinflammatory Mechanisms. Current Opinion in Lipidology, 24, 371. https://doi.org/10.1097/MOL.0b013e328363d298

[10] Raman, P., Krukovets, I., Marinic, T.E., Bornstein, P. and Stenina, O.I. (2007) Glycosylation Mediates Up-Regulation of a Potent Antiangiogenic and Proatherogenic 
Protein, Thrombospondin-1, by Glucose in Vascular Smooth Muscle Cells. Journal of Biological Chemistry, 282, 5704-5714. https://doi.org/10.1074/jbc.M610965200

[11] Murphy, M., Godson, C., Cannon, S., Kato, S., Mackenzie, H.S., Martin, F. and Brady, H.R. (1999) Suppression Subtractive Hybridization Identifies High Glucose Levels as a Stimulus for Expression of Connective Tissue Growth Factor and Other Genes in Human Mesangial Cells. Journal of Biological Chemistry, 274, 5830-5834. https://doi.org/10.1074/jbc.274.9.5830

[12] Tada, H., Kawai, H., Ishii, H., Nomura, K., Urayama, T. and Isogai, S. (1995) Thrombospondin Modulates Adhesion, Proliferation and Production of Extracellular Matrix in Mesangial Cells. The Tohoku Journal of Experimental Medicine, 177, 293-302. https://doi.org/10.1620/tjem.177.293

[13] Poczatek, M.H., Hugo, C., Darley-Usmar, V. and Murphy-Ullrich, J.E. (2000) Glucose Stimulation of Transforming Growth Factor- $\beta$ Bioactivity in Mesangial Cells Is Mediated by Thrombospondin-1. The American Journal of Pathology, 157, 1353-1363. https://doi.org/10.1016/S0002-9440(10)64649-4

[14] Yevdokimova, N., Wahab, N.A. and Mason, R.M. (2001) Thrombospondin-1 Is the Key Activator of TGF- $\beta 1$ in Human Mesangial Cells Exposed to High Glucose. Journal of the American Society of Nephrology, 12, 703-712. https://doi.org/10.1681/ASN.V124703

[15] Li, S.S., Ivanoff, A., Bergström, S.E., Sandström, A., Christensson, B., Nerven, J.V., Sundqvist, K.G., et al. (2002) T Lymphocyte Expression of Thrombospondin-1 and Adhesion to Extracellular Matrix Components. European Journal of Immunology, 32, 1069-1079.

https://doi.org/10.1002/1521-4141(200204)32:4<1069::AID-IMMU1069>3.0.CO;2-E

[16] Belmadani, S., Bernal, J., Wei, C.C., Pallero, M.A., Dell'Italia, L., Murphy-Ullrich, J.E. and Berecek, K.H. (2007) A Thrombospondin-1 Antagonist of Transforming Growth Factor- $\beta$ Activation Blocks Cardiomyopathy in Rats with Diabetes and Elevated Angiotensin II. The American Journal of Pathology, 171, 777-789. https://doi.org/10.2353/ajpath.2007.070056

[17] Lee, T., Esemuede, N., Sumpio, B.E. and Gahtan, V. (2003) Thrombospondin-1 Induces Matrix Metalloproteinase-2 Activation in Vascular Smooth Muscle Cells. Journal of Vascular Surgery, 38, 147-154. https://doi.org/10.1016/S0741-5214(02)75468-2

[18] Qian, X., Wang, T.N., Rothman, V.L., Nicosia, R.F. and Tuszynski, G.P. (1997) Thrombospondin-1 Modulates Angiogenesis in Vitro by Up-Regulation of Matrix Metalloproteinase-9 in Endothelial Cells. Experimental Cell Research, 235, 403-412. https://doi.org/10.1006/excr.1997.3681

[19] American Diabetes Association (2010) Standard of Medical Care in Diabetes. Diabetes Care, 30, 23.

[20] Lang, R.M., Bierig, M., Devereux, R.B., Flachskampf, F.A., Foster, E., Pellikka, P.A., Stewart, W.J., et al. (2005) Recommendations for Chamber Quantification: A Report from the American Society of Echocardiography's Guidelines and Standards Committee and the Chamber Quantification Writing Group, Developed in Conjunction with the European Association of Echocardiography, a Branch of the European Society of Cardiology. Journal of the American Society of Echocardiography, 18, 1440-1463. https://doi.org/10.1016/j.echo.2005.10.005

[21] Devereux, R.B. (1987) Detection of Left Ventricular Hypertrophy by M-Mode Echocardiography. Anatomic Validation, Standardization, and Comparison to Other Methods. Hypertension, 9, II19-II26.

https://doi.org/10.1161/01.HYP.9.2 Pt 2.II19 
[22] Sullivan, D.R., Marwick, T.H. and Freedman, S.B. (1990) A New Method of Scoring Coronary Angiograms to Reflect Extent of Coronary Atherosclerosis and Improve Correlation with Major Risk Factors. American Heart Journal, 119, 1262-1267. https://doi.org/10.1016/S0002-8703(05)80173-5

[23] Wolk, R., Berger, P., Lennon, R.J., Brilakis, E.S. and Somers, V.K. (2003) Body Mass Index: A Risk Factor for Unstable Angina and Myocardial Infarction in Patients with Angiographically Confirmed Coronary Artery Disease. Circulation, 108, 2206-2211. https://doi.org/10.1161/01.CIR.0000095270.85646.E8

[24] Gensini, G.G. (1983) A More Meaningful Scoring System for Determining the Severity of Coronary Heart Disease. The American Journal of Cardiology, 51, 606. https://doi.org/10.1016/S0002-9149(83)80105-2

[25] Nurkalem, Z., Hasdemir, H., Ergelen, M., Aksu, H., Sahin, I., Erer, B., Eren, M., et al. (2010) The Relationship between Glucose Tolerance and Severity of Coronary Artery Disease Using the Gensini Score. Angiology, 61, 751-755. https://doi.org/10.1177/0003319710373747

[26] Sianos, G., Morel, M.A., Kappetein, A.P., Morice, M.C., Colombo, A., Dawkins, K., Serruys, P.W., et al. (2005) The SYNTAX Score: An Angiographic Tool Grading the Complexity of Coronary Artery Disease. EuroIntervention, 1, 219-227.

[27] Friedewald, W.T., Levy, R.I. and Fredrickson, D.S. (1972) Estimation of the Concentration of Low-Density Lipoprotein Cholesterol in Plasma, without Use of the Preparative Ultracentrifuge. Clinical Chemistry, 18, 499-502.

https://doi.org/10.1093/clinchem/18.6.499

[28] Barillari, G., Iovane, A., Bonuglia, M., Albonici, L., Garofano, P., Di Campli, E., Ensoli, B., et al. (2010) Fibroblast Growth Factor-2 Transiently Activates the p53 Oncosuppressor Protein in Human Primary Vascular Smooth Muscle Cells: Implications for Atherogenesis. Atherosclerosis, 210, 400-406. https://doi.org/10.1016/j.atherosclerosis.2010.01.006

[29] Osada-Oka, M., Ikeda, T., Akiba, S. and Sato, T. (2008) Hypoxia Stimulates the Autocrine Regulation of Migration of Vascular Smooth Muscle Cells via HIF-1 $\alpha$-Dependent Expression of Thrombospondin-1. Journal of Cellular Biochemistry, 104, 1918-1926. https://doi.org/10.1002/jcb.21759

[30] Takahashi, M., Oka, M., Ikeda, T., Akiba, S. and Sato, T. (2008) Role of Thrombospondin-1 in Hypoxia-Induced Migration of Human Vascular Smooth Muscle Cells. Yakugakuzasshi: Journal of the Pharmaceutical Society of Japan, 128, 377-383. https://doi.org/10.1248/yakushi.128.377

[31] Yabkowitz, R., Mansfield, P.J., Ryan, U.S. andSuchard, S.J. (1993) Thrombospondin Mediates Migration and Potentiates Platelet-Derived Growth Factor-Dependent Migration of Calf Pulmonary Artery Smooth Muscle Cells. Journal of Cellular Physiology, 157, 24-32. https://doi.org/10.1002/jcp.1041570104

[32] Narizhneva, N.V., Razorenova, O.V., Podrez, E.A., Chen, J., Chandrasekharan, U.M., DiCorleto, P.E., Byzova, T.V., et al. (2005) Thrombospondin-1 Up-Regulates Expression of Cell Adhesion Molecules and Promotes Monocyte Binding to Endothelium. The FASEB Journal, 19, 1158-1160. https://doi.org/10.1096/fj.04-3310fje

[33] Muraishi, A., Capuzzi, D.M. and Tuszynski, G.P. (1993) Binding of Thrombospondin to Human Plasma Lipoproteins. Biochemical and Biophysical Research Communications, 193, 1145-1151. https://doi.org/10.1006/bbrc.1993.1745

[34] Majack, R.A., Goodman, L.V. and Dixit, V.M. (1988) Cell Surface Thrombospondin Is Functionally Essential for Vascular Smooth Muscle cell Proliferation. The Journal of Cell Biology, 106, 415-422. https://doi.org/10.1083/jcb.106.2.415

[35] Stouffer, G.A., Hu, Z., Sajid, M., Li, H., Jin, G., Nakada, M.T., Runge, M.S., et al. 
(1998) $\beta 3$ Integrins Are Upregulated after Vascular Injury and Modulate Thrombospondin- and Thrombin-Induced Proliferation of Cultured Smooth Muscle Cells. Circulation, 97, 907-915. https://doi.org/10.1161/01.CIR.97.9.907

[36] McGillicuddy, F.C., O’Toole, D., Hickey, J.A., Gallagher, W.M., Dawson, K.A. and Keenan, A.K. (2006) TGF- $\beta 1$-Induced Thrombospondin-1 Expression through the p38 MAPK Pathway Is Abolished by Fluvastatin in Human Coronary Artery Smooth Muscle Cells. Vascular Pharmacology, 44, 469-475. https://doi.org/10.1016/j.vph.2006.03.002

[37] Topol, E.J., McCarthy, J., Gabriel, S., Moliterno, D.J., Rogers, W.J., Newby, L.K., Daley, G.Q., et al. (2001) Single Nucleotide Polymorphisms in Multiple Novel Thrombospondin Genes May Be Associated with Familial Premature Myocardial Infarction. Circulation, 104, 2641-2644. https://doi.org/10.1161/hc4701.100910

[38] Yamada, Y., Izawa, H., Ichihara, S., Takatsu, F., Ishihara, H., Hirayama, H., Yokota, M., et al. (2002) Prediction of the Risk of Myocardial Infarction from Polymorphisms in Candidate Genes. New England Journal of Medicine, 347, 1916-1923. https://doi.org/10.1056/NEJMoa021445

[39] Carlson, C.B., Liu, Y., Keck, J.L. and Mosher, D.F. (2008) Influences of the N700S Thrombospondin-1 Polymorphism on Protein Structure and Stability. Journal of Biological Chemistry, 283, 20069-20076. https://doi.org/10.1074/jbc.M800223200

[40] Choi, K.Y., Kim, D.B., Kim, M.J., Kwon, B.J., Chang, S.Y., Jang, S.W., Kim, J.H., et al. (2012) Higher Plasma Thrombospondin-1 Levels in Patients with Coronary Artery Disease and Diabetes Mellitus. Korean Circulation Journal, 42, 100. https://doi.org/10.4070/kcj.2012.42.2.100

[41] Stenina, O.I., Krukovets, I., Wang, K., Zhou, Z., Forudi, F., Penn, M.S., Plow, E.F., et al. (2003) Increased Expression of Thrombospondin-1 in Vessel Wall of Diabetic Zucker Rat. Circulation, 107, 3209-3215. https://doi.org/10.1161/01.CIR.0000074223.56882.97

[42] Kirma, C., Akcakoyun, M., Esen, A.M., Barutcu, I., Karakaya, O., Saglam, M., et al. (2007) Relationship between Endothelial Function and Coronary Risk Factors in Patients with Stable Coronary Artery Disease. Circulation Journal, 71, 698-702. https://doi.org/10.1253/circj.71.698

[43] Hsu, S.C., et al. (1996) Inhibition of Angiogenesis in Human Glioblastomas by Chromo Some 10 Induction of Thrombospondin-1. Cancer Research, 56, 5684-5691.

[44] Nör, J.E., Mitra, R.S., Sutorik, M.M., Mooney, D.J., Castle, V.P. and Polverini, P.J. (2000) Thrombospondin-1 Induces Endothelial Cell Apoptosis and Inhibits Angiogenesis by Activating the Caspase Death Pathway. Journal of Vascular Research, 37, 209-218. https://doi.org/10.1159/000025733

[45] Schultz-Cherry, S., Lawler, J. and Murphy-Ullrich, J.E. (1994) The Type 1 Repeats of Thrombospondin 1 Activate Latent Transforming Growth Factor-Beta. Journal of Biological Chemistry, 269, 26783-26788. https://doi.org/10.1016/S0021-9258(18)47087-1

[46] Schultz-Cherry, S., Ribeiro, S., Gentry, L. and Murphy-Ullrich, J.E. (1994) Thrombospondin Binds and Activates the Small and Large Forms of Latent Transforming Growth Factor-Beta in a Chemically Defined System. Journal of Biological Chemistry, 269, 26775-26782. https://doi.org/10.1016/S0021-9258(18)47086-X

[47] Yang, S.N., Burch, M.L., Tannock, L.R., Evanko, S., Osman, N. and Little, P.J. (2010) Transforming Growth Factor- $\beta$ Regulation of Proteoglycan Synthesis in Vascular Smooth Muscle: Contribution to Lipid Binding and Accelerated Atherosclerosis in Diabetes. Journal of Diabetes, 2, 233-242.

https://doi.org/10.1111/j.1753-0407.2010.00089.x 